\title{
Socio-cultural deterrents to family planning practices among Swazi women
}

\author{
IS Ziyani, D Litt et Phil, student : Unisa, lecturer : University of Swaziland, \\ VJ Ehlers, Department of Health Studies, Unisa \\ LJ King, formerly from the Department of Health Studies, Unisa
}

\section{Abstact}

To investigate deterrents to family planning practices among Swazi women, 205 structured interviews were conducted with conveniently selected women in the four geographical regions of Swaziland. The Statistical Package for Social Sciences (SPSS) was used to analyse data. These results revealed that cultural practices, religious beliefs, gender issues and health care practices were the main barriers to the use of contraceptives among Swazi women. Recommendations were suggested regarding the education of men, women, adolescents and the entire society about contraceptive practices.

\section{Abstrak}

Ten einde navorsing te doen oor weerhoudende faktore wat gesinsbeplanningspraktyke onder Swazi vroue beïnvloed, is 205 gestruktureerde onderhoude gevoer met gerieflik beskikbare vrouens in die vier geografiese streke van Swaziland. Die "Statistical Package for Social Sciences" (SPSS) was gebruik om die data te ontleed. Die resultate het onthul dat kulturele praktyke, godsdienstige opvattings, geslags ("gender") vraagstukke en gesondh eidspraktyke die belangrikste weerhoudende faktore was wat die gebruik van kontraseptiewe middels onder Swazi vrouens beïnvloed het. Aanbevelings is gedoen aangaande die opvoeding oor kontraseptiewe gebruike van mans, vroue en adolosente en die hele gemeenskap.

Key words: adolescents, contraceptives, childbearing women, family planning, family planning centres, family planning practices, methods of family planning, Swaziland.

\section{Introduction}

In developing countries including Swaziland, women spend a significant number of years either pregnant, lactating or doing both at the same time. Their fate is compounded by the fact that $27 \%$ of Swazi adolescents (15-19 years of age) become pregnant (Ministry of Health and Social Welfare Report 2001-2005:11). The Health Statistical Report (HSR 1997:6) further reported that $6 \%$ of recorded deliveries were from women older than 35 years of age, and $15 \%$ of women had given birth to more than five children. The obstetric risk factors that Swazi women are subjected to, imply that the chances of dying from causes related to child bearing in Swaziland are estimated to be 1 per 69 live births. In contrast, the risk of maternal death in industrialised countries averages 27 per 100000 live births (Hatcher \& Kowal 1999:3).

The World Health Report (1998:97) maintains that, for every maternal death about 10-15 surviving women suffer illness or severe disability as a consequence of pregnancy. Family planning therefore appears to be the main route for improving maternal health in Swaziland according to
Campbell (1997:186). As much as Sengal (1993:51) noted that family planning services have produced effective results in the developed countries, in some underdeveloped countries like Swaziland, a "contradiction" exists as women are willing to promote their health through family planning services, but fail to translate this willingness into concrete actions even when contraceptives are available (Kalanzi 1991:26).

This apparent gap between knowledge and practice might be explained by looking at cultural institutions, because many Swazi women might fear losing their fertility as a result of some contraceptive practices (Silberschmidt \& Rasch 2001:1819). The loss of fertility might jeopardise Swazi women's social status as potential husbands shun them (Gule 1993:242) and this could leave them with a lifelong stigma of being infertile, or subfertile and/or unmarried (WLSA 1998:204). According to Ndubani and Hojer (2001:110), the gap may also be explained by the fact that dominant "male attitudes" might interfere with the women's expressed desires to control their families' sizes. For example, in the Swazi culture a husband may be a significant constraint to the use of contraceptives (Holland, Ramazanoglu, Sharpe 
\& Thomson 1992:645-674). Similarly the use of abortion as a family planning method is an illegal practice in Swaziland (Ankomah, Aloo-Obunga, Chu \& Manlagnit 1997:45), and Swazi women may thus be obliged to seek unsafe abortions for family planning purposes. Despite illness and high mortality rates being associated with high fertility and unsafe abortions, male-dominated legal and religious structures prevent women in many Sub-Saharan Africa (SSA) countries, including Swaziland, from using contraceptives.

As many as $82,0 \%$ of Swazi's who participated in a survey conducted during 1998 were knowledgeable about contraceptives, but the user rate was as low as $29,0 \%$ and the drop out rate was $65,0 \%$ (SNAP 2000:13; Health Statistical Report 1997:6). The apparent dichotomy which exists between the knowledge about and utilisation of contraceptives among Swazi women, requires further investigations if more Swazi women are to access and utilise contraceptive services.

Swaziland is one of the smallest countries in Southern Africa, covering $17600 \mathrm{sq}$ kilometres. It has a population of approximately one million. Swaziland is a landlocked country, which is almost completely surrounded by the Republic of South Africa (RSA) except for the eastern part, which is bordered by Mocambique.

According to Okpaluba, Hlatshwayo and Khumalo (1997:271), Swaziland has a largely homogenous society. Customs and traditions have been preserved, reflecting the Kingdom's unique national identity. In the Swazi society, the family occupies a central position in social life because of its traditional functions of procreation and socialisation (Kasenene 1993:74). Male headship is important in family formation, explaining preference for boy children in the Swazi society (WLSA 1998:24). This cultural practice, as observed by Gule (1993:243), contributes to the high birth rate in Swaziland. The total fertility rate of Swaziland is among the world's highest, being 6,4 births per woman as recorded in the National Development Strategy (1998:50).

Women make-up $50,0 \%$ of the population, and about one third of these women are at the childbearing stage, ranging from 20 to 49 years (HSR 1997:6). This is particularly significant when noticing that approximately $49,0 \%$ of the population are younger than 15 years of age (Ministry of Health and Social Welfare Report 2001a:2), and a further $28,8 \%$ is under the age of 20 years according to SNAP (1996:3). This scenario has serious consequences for the future population, as the Swazi population could double by the year 2011 , unless specific precautions are introduced (Development Plan 1996/7-1998/9:50).

Although women constitute half of the Swazi population, the National Development Strategy (1998:57) notes that women are customarily a marginalised group. Their status is seen and valued in the reproductive arena, and infertile women would be seen as having failed in mar- riage because they did not produce children (Okpaluba et al 1997:269). Indeed, children are generally seen as the only means of support in old age. The more children parents have, by implication, the greater their security will be in their old age. Consequently, Kasenene (1993:77) points out that large families are the norm in Swaziland. The minority status of women perpetuates even in decisions related to women's health, hence some women fail to practise family planning because of husband/partner disapproval (WLSA 2000:136). Family planning programmes in Swaziland, as observed by WLSA (1998:201), appear to centre on persuading men to allow their wives or partners to use contraceptives.

Another cultural factor that contributes to the high fertility rate in Swaziland is the continued practice of polygamy in Swaziland (Dlamini 1997:294). Having more than one wife is seen as enhancing the status of men in the society. An important factor, however, is that the more wives a man has, the more children he is likely to have, as each wife has to bear children in order to justify her social position. In fact, Kasenene (1993:77) states that in Swazi religion, 'to have children is to rise from the dead'. The practice of polygamy continues to exist in Swaziland, contributing to high population growth rates and ineffective family planning practices.

Russell (1993:48) reported that another contributing cause to the high fertility rate in Swaziland is extramarital conception. Although many Swazi's marry at a late stage ( 30 years of age or even later), most people engage in sex at the average age of 17 years in the case of girls, and 19 years in the case of boys (NPASMI 1997-2000:11). Evidence of such engagement in early sexual intercourse can be found in the high rate $(27,0 \%)$ of adolescent pregnancies, as indicated by UNICEF (1994:11). According to the Health Statistical Report of 1997 , a further $0,5 \%$ of deliveries conducted in health care facilities occur among girls younger than 15 years of age (HSR 1997:6). This scenario reflects a need for the best possible health care to prevent unplanned pregnancies by using effective contraceptives (Population Report (2001:3).

\section{Table 1: Population growth of Swaziland: 1986-2001}

\begin{tabular}{|l|l|l|l|}
\hline & 1986 & 1996 & 2001 \\
\hline Total population & 668124 & 937747 & 1095094 \\
\hline Crude birth rates/1000 & 49,1 & 42,8 & 37,7 \\
\hline Crude death rates/1000 & 12,6 & 10,1 & 8,7 \\
\hline $\begin{array}{l}\text { Rate of natural increase } \\
\text { per annum }\end{array}$ & 3,65 & 3,27 & 2,9 \\
\hline Total births (estimates) & 33402 & 40766 & 44633 \\
\hline
\end{tabular}

(Source: Ministry of Health and Social Welfare Report 2001-2005:2) 


\section{Problem statement}

Contraceptives are available in Swaziland. Persistently high fertility rates indicate that women fail to use effective contraceptives. Barriers to the use of (available) contraceptives need to be identified in order to enable more Swazi women to access and utilise effective contraceptives.

\section{Objectives of the study}

The main purpose of this study was to identify barriers preventing Swazi women from using contraceptives.

\section{Research questions}

The following research question was posed:

Which factors/barriers prevent Swazi women from using contraceptives?

\section{Significance of the research}

Conducting a study on factors which deter women from using family planning services is particularly relevant for health care providers, since more information about family planning attitudes and practices could contribute to the development of programmes that are particularly relevant to childbearing women in Swaziland.

In addition, policies on family planning can be formulated which could be culturally more acceptable to Swazi women and men. The findings from this study could be used to develop adolescent health programmes, which will address issues such as sexuality, adolescent pregnancies, and family planning.

Educational programmes presented via the media, and peer education at public gatherings can be developed in order to empower women on sexuality issues. Nurse educators can also use the findings of this study to teach student midwives and community health nurses about the sociocultural aspects of contraceptive practices.

By using effective contraceptives, matemal deaths amongst Swazi women could be reduced by as much as $33 \%$ (NDS 1998:50). One fundamental goal of family planning, as outlined by the Centre for Disease Control (CDC 1999:8), is to make "every child a wanted child". Hence the abortion rate in Swaziland can also be reduced if effective contraceptives were used by the majority of women who did not desire pregnancies at any specific stage of their lives.

\section{Literature review}

In most African countries, including Swaziland, customs tend to emphasise the importance of childbearing (Ndubani \& Hojer 2001:110). Consequently, family planning services may be poorly accepted in these societies. In Swaziland, contraceptive prevalence is low ( $29 \%$ according to SNAP 2000:6). This minimal use of modern contraceptives in
Swaziland, could be due to socio-cultural factors, including men's attitudes towards the use of contraceptives and gender issues in the Swazi culture affecting contraceptive practices. Such gender issues include the Swazi kinship structure, partners' disapproval of using contraceptives, bias and prejudice towards contraceptives, women's status, the value of children in the Swazi culture, the high infant and child mortality rate in Swaziland, the quality of contraceptive services and access barriers to using contraceptives in Swaziland.

\section{- Men's attitudes towards contraceptives}

Mbizvo and Adamchak (1992:52) observed that there is a relative lack of male contraceptive data in the scientific literature. Most studies on fertility and family planning issues, focus on women, and ignore men. These studies according to Bankole and Singh (1998:15) overlooked the primary fertility decision-makers in most African countries . This is particularly relevant to societies like Swaziland where women are considered to be minors to the extent that their husbands' approval is required for the women to use contraceptives (WLSA 1998:200).

Mbizvo and Adamchak (1992:52) conducted a survey in Zimbabwe to ascertain male knowledge, attitudes and behaviours relating to fertility regulatory methods directed towards men. Stratified cluster sampling procedures were used, and a representative sample of 711 households completed questionnaires. The results showed that the majority of the respondents knew about female contraceptive pills $(74,0 \%)$. Condom knowledge was only $37,8 \%$, but the user rate was low $(6,0 \%)$. The main reason for disapproval of family planning was the desire for additional children.

In another survey by Chipfakacha (1993), 260 Botswana men were interviewed by the District Health Team of Botswana. Their knowledge, attitudes, practices and experiences with regard to family planning was investigated. The results demonstrated high $(74,0 \%)$ knowledge of modern contraceptives. With regard to spousal communication about family planning issues, the majority $(65,0 \%)$ of respondents were non-conversant about family planning issues, and regarded family planning issues as women's business. Contrary to the above statement, these men would be angry to the point of beating their wives, if they were to discover that the women were using family planning methods. These men, according to Chipfakacha (1993:82), perceived family planning methods as promoting infidelity among women. The negative attitudes of men toward contraceptives were observed by Zwane (2000:9) as the main deterrent to the use of contraceptives by Swazi women.

Odinegwu (1999) conducted a survey amongst a sample of 927 married men and women in Nigeria. A factor analysis process was used to measure respondents' attitudes towards, and utilisation of, contraceptive practices. The results revealed that $76,0 \%$ of respondents had a sound knowledge about contraceptives, but only $28,0 \%$ were using contracaeptives at the time of the investigation. Fewer men 
$(42,0 \%)$ than women $(50,0 \%)$ had ever used contraceptives (Odinegwu 1999:87). Even if women were inclined to use contraceptives, culturally they might not succeed as social support (especially from their male partners) was important for the success of maintained contraceptive use. According to Erasmus and Bekker (1996:14) this is also the case with Swazi women who lacked social support and failed to use contraceptives effectively.

\section{- Gender issues}

According to Barker and Rich (1992:199) socio-cultural factors which are grounded in gender relations that enforce the subordinate status of women, impede to the use of family planning services. In Swaziland, for example, high birth rates prior to marriage are an established social pattern (Shongwe 1993:73). This is confirmed by certain cultural practices regarding the handling of prenatal births, which include compensation payment for the girls' parents, the buying of offspring by their parents, and the absorption of children by the rural homestead (Russell 1993:43). When a woman who has born premarital children finally gets married, she is also expected to bear many children in the new family in order to justify her marital status (Russell, 1993:43).

Similarly, in a situation whereby a man has fathered children from many women, the competition as to which woman will win his hand in marriage will probably be won by the woman who has born the largest number of children (Rwomire 1991:62). The WLSA (1998:205) points out that young women have premarital children in order to prove their ideal status as women, to their future husbands and families- in-law. Contrary to this situation, a woman who is barren is stigmatised and her husband may decide to divorce her. In such a situation a substitute wife, usually a young relative, might be secured in order to produce children on behalf of the barren woman (WLSA 1998:205). This gender disparity against women signifies a need to educate women about their reproductive rights and about the use of effective contraceptives. In a report by Gule (1993:242) a number of socio-cultural and gender issues were identified as the main deterrent to family planning in Swaziland.

\section{Kinship structure}

According to Gule (1993:243), the extended family system in Swaziland is a deterrent to family planning practices, since all decisions, even those that relate to health and family planning, must be endorsed by the extended family, including the family-in-law in the case of married women. Failure to comply with the demands of a large family can result in a variety of social problems. Motsa (1991:29) suggests that a Swazi woman may rather be advised to consult a traditional healer for family spacing purposes, than to limit the number of children by using contraceptives in order to maintain the approval of her extended family, including the family-in-law.

\section{Partners' disapproval of using contraceptives}

Culturally, Swazi women are not regarded as equal partners in marriage, but are considered to be inferior partners who cannot obtain contraceptives if their husbands should disapprove. Male dictatorship in Swaziland results in a lack of effective communication between couples on family planning issues (Okore, Mahindi \& Dlamini 1993:92). Consequently, many Swazi women fail to make effective use of family planning practices.

In Nigeria, misconceptions and negative attitudes toward family planning were found to be displayed by both men and women. Otiode, Oronsaye and Okonofua (2001:77) conducted twenty focus group discussions in Benin city in Nigeria. The purpose of the study was to explore attitudes and beliefs concerning the use of contraceptives. The results revealed negative attitudes toward the use of contraceptives in Benin city in Nigeria.

\section{Bias and prejudice towards the use of contraceptives}

Some Swazi men who know about contraceptive methods might feel that family planning is a white man's creation to reduce African numbers (Okore et al 1993:93). Others assert that family planning practices are against Swazi culture and that its use is against the will of God. Men are not totally to blame for their lack of knowledge and minimal participation in family planning activities. In general, family planning programmes are female oriented and are incorporated in maternal and child health services in most health care centres in Swaziland. In addition, these services are usually headed by female staff (Gule 1993:243). Male motivators have been trained to encourage their fellow men to use family planning methods, and to distribute nonprescriptive contraceptives such as condoms. However, very few men use family planning methods, and the majority still view family planning to be a foreign concept (Mkhonta 1999:8). The Swaziland Government Strategic Plan (2001-2005:13) addressed male involvement in family planning and reproductive issues by involving male motivators, educators and distributers of male oriented family planning methods. This effort is aimed at promoting open communication about sexuality issues among partners, and increasing contraceptive use.

\section{Swazi women's status}

In Swaziland, a woman's status is associated with motherhood. The more children a woman has, the more status she commands in society. On the contrary, childlessness is considered to be a social and cultural handicap (Gule 1993:242). It is for this reason that a woman cannot voluntarily use family planning as her status might be jeopardised if she should do so. Decisions about fertility control rest solely with the husband, who is the head of the Swazi family (Mkhonta 1999:4).

Sukati (1998:226) conducted a study that was aimed at understanding the views of Swazi women towards men's lack of commitment in family planning practices. In the study, a sample comprising 381 women selected from 21 enumerated areas, participated in face to face interviews. They represented rural, peri-urban and industrial settings, and 
their ages ranged from 15 to 49 . The results showed that women identified a need for health providers to target men on health related issues including family planning (Sukati 1998:226). It became evident from the study that the health providers sidelined the decision-makers in family planning issues such as family planning methods. In view of this shortcoming in the health care delivery system, women expressed a need to access female condoms. Such devices would empower women to use their reproductive rights should men refuse to use condoms (Sukati 1998:228). Indeed, Okore et al (1993:94) observed that only free and emancipated women could fully participate in practising family planning decisions and actions. This situation overlooks the fact that for family planning to work, both partners should be involved (Rees 1995:34). According to Tadiar and Robinson (1996:77), some methods of family planning require the cooperation of men. These include periodic $a b-$ stinence, incomplete intercourse by withdrawal, male sterilisation, and the use of male as well as female condoms.

\section{The value of children in the Swazi culture}

In Swaziland children are desirable and valued. Men boast about their virility, and women about their fertility (WLSA 1998:204). The value of children is reflected in the National Health and Social Welfare Policy, which indicates that "providers of reproductive services shall respect the right of couples and individuals to decide freely and responsibly about the number and spacing of their children" (Ministry of Health and Social Welfare $200 \mathrm{lb}$ : 18).

In Swaziland children are still considered to be a family resource and they bring joy to the family. Gule (1993:243) noted that having a large family in Swaziland is necessary to ensure adequate and continued support during old age. The social support provided by children is confirmed by the absence of social services for disadvantaged and senile members of the Swazi society. Lack of Government commitment to social services justify the need for partners to bear many children in order to secure their future. Furthermore, Swaziland is a patriarchal society, maintaining pressure on women to bear sons in order to carry on the family name. Historically, the perpetuation of the male line was important for the economic viability of individual families and for nation building (WLSA 1998:204). This practice is a significant deterrent to family planning practices among Swazi men and women.

\section{Infant and child mortality rates in Swaziland}

The infant mortality rate in Swaziland is reportedly 68 per 1000 live births (Gule 1993:242). Consequently, Swazi women resort to having many children so that in case some of their children die (a highly probable occurrence in Swaziland) there will be some surviving children. In view of the reality that some of their children might die during childhood, Swazi women might hesitate to use contraceptives, since it may lead to childless or small families, should any number of their children die. The implications of Gule's (1993) report is to reduce infant and child mortality rates concurrently with the implementation of effective family planning programmes in Swaziland.

\section{The quality of family planning services in Swaziland}

The negative attitudes of family planning providers, lack of qualified personnel, absence of client friendly policies and lack of resources including privacy in counselling family planning clients, could deter clients from utilising family planning services (Galvao, Diaz, Diaz Osis, Clark \& Ellertson 1999:168). For example, a report from Ecuador by AbouZahr, Vlassorff and Kumar (1996:454) revealed that women failed to use family planning services because of rigid timetables and stipulations imposed on clients. Conversely, Abdool Karim, Abdool Karim and Preston-Whyte (1992:392) noted that poor attitudes of clinic staff were identified as the main barrier to the utilisation of effective family planning practices among adolescents in Durban in the RSA. Hiltabiddle (1996:63) is of the opinion that, if family planning providers could be more conversant regarding adolescent sexuality issues, more adolescents might utilise effective family planning methods.

\section{Access barriers}

Access to family planning services is determined by physical and logistical factors, including the proximity of family planning services to the homesteads, as well as the availability of transport. Economic factors such as cash to purchase pills or condoms, and the cost of forfeiting wages as well as paying for transport also function as barriers to the use of contraceptives (AbouZahr et al 1996:454).

The Ministry of Health and Social Welfare of Swaziland embarked on a community-based family planning programme, which aims to make contraceptive services more accessible to clients (Ministry of Health \& Social Welfare $2001 \mathrm{~b}: 3$ ). Before the inception of the community-based family planning programme, contraceptives were available at the regular health care facilities. Some of the health care centres are geographically inaccessible, with a limited variety of family planning methods, minimal counselling services and lack of trained personnel to provide particular methods of contraception (NDS 1998:169). These factors might further contribute to limited use of family planning services among Swazi women. The WHO (1995) recommends community-based family planning programmes, which are acceptable and convenient to communities as well as affordable when compared with clinic-based services.

\section{Research methodology}

A quantitative descriptive study was conducted, using structured interviews to identify factors/barriers impacting on the use of contraceptives by Swazi women.

\section{Sample}

A total of 205 mothers who attended health care facilities and who agreed to be interviewed constituted the conveniently selected sample for this survey. Although the women who attended health care facilities were conveniently selected by the nurses working at these centres, one centre 
was selected in each district in Swaziland. This selection of the participating centres was done by the Department of Statistics of the Ministry of Health and Social Welfare of Swaziland.

\section{Research instrument}

Face to face structured interviews were conducted with the selected participants. The items included in the structured interview schedule were derived from a literature study, from previous studies done on similar issues in Swaziland, and from the results of focus group interviews conducted by the researcher prior to this survey.

Polit and Hungler (1995:253) advised that when developing a research instrument four important dimensions should be observed, namely structure, quantifiability, researcher obtrusiveness and objectivity. The instrument developed for this study ensured that data was collected according to a structured plan that indicated the information to be gathered and the method of collecting data. The structured interview included questions that could be completed quickly, analysed easily and enabled direct comparisons between variables. However, open-ended questions were also included in order for respondents to reveal information in their own words. Hicks (1996:16) asserted that both fixed and open-ended questions should be used in order to produce rich data. Responses to open-ended questions were grouped into similar categories and subjected to analysis, with the assistance of a statistician from the University of Swaziland.

\section{Pretest}

A pretest is a method used to test the instrument of a proposed study in order to refine the research tool before the main study is executed. The rationale for pretesting the research tool was to

- develop or refine the research instrument

- $\quad$ identify problems with the design of the instrument

- $\quad$ examine the reliability and validity of the research instrument

Ten respondents were recruited from health care centres as well as local schools. These ten persons who participated in the pretest were excluded from participating in the main survey. Items which were perceived to be ambiguous were modified and further tested for clarity by interviewing five additional respondents.

\section{Conducting the interviews}

Interviews were conducted by the researcher and two research assistants using the structured interview schedule. The interviews were conducted over a period of six months. At the end of each day, interview forms were collected by the researcher and checked for completeness and clarity of information. Once all the required data had been collected, it was given to the statistician for compilation and analysis.

The instrument was developed in such a way that data would be easily quantifiable. Polit and Hungler (1995:254) advise that the researcher should collect data after having spent time with respondents. To this end, the researcher was introduced to the interview respondents, had introductory discussions with each group and became familiar with the group members. Such efforts were made to eliminate obtrusiveness, which can occur when the respondents are not familiar with the interviewer. Finally, the researcher maintained objectivity when collecting data by utilising different research assistants. Polit and Hungler (1995:254) state that objectivity is maintained when independent researchers examine the same phenomenon and yield similar findings.

\section{Advantages and disadvantages of interviews}

According to Polit and Hungler (1995:290), the advantages of collecting data using face to face interviews include:

- A high response rate: a well-designed interview study achieves $80 \%-90 \%$ response rate, thus reducing bias that might exist if the response rate was low. (In case of low response rates - such as would normally be expected when postal questionnaires are used, the researcher cannot assume that the persons who completed and returned questionnaires revealed knowledge, attitudes and perceptions similar to those who did not return completed questionnaires).

- High audience coverage: many individuals, such as illiterate, elderly, blind or physically deformed people cannot complete questionnaires but can provide verbal responses to questions during an interview.

- Clarity: interviews offer some protection against ambiguous questions. Rephrasing can offer a better clarification of the question for specific individuals.

- Supplementary data may be obtained duirng an interview, where the interviewer can observe and judge the respondents' level of understanding and degree of cooperativeness.

The disadvantages of interviews include:

- interviewer bias

- $\quad$ anonymity of respondents cannot be maintained

- interviews tend to be costly and time consuming as only one person can be interviewed at any given time by one interviewer .

The advantages of using structured interviews as a method of collecting data during this study, outweighed the disadvantages thereof.

\section{Analysis of data collected during structured interviews}

Data from the structured interviews were analysed by means 
of the SPSS computer program. This was made possible by assistance from the Department of Statistics at the University of Swaziland.

\section{Reliability, validity and bias}

In order for the research findings to be acceptable to the scientific community, it was important to examine the aspects of reliability, validity and bias.

\section{Reliability}

Reliability is the degree of consistency or dependability with which a research instrument measures the attributes it is designed to measure (Burnad \& Morrison 1994:74). Therefore, reliability is concerned with the consistency, stability and repeatability of the informants' accounts as well as the investigators' ability to collect and record information accurately (Brink \& Wood 1998:299). In this study, reliability was enhanced by means of the following:

- Questions were pretested and yielded similar findings when compared with the main study.

- The interviews were conducted by three people (the researcher and two assistants) and in all instances yielded similar findings.

\section{Validity}

Validity, as observed by Polit and Hungler (1995:353), in research should be concerned with the accuracy and truthfulness of scientific findings. A valid study should demonstrate what actually exists and a valid instrument should measure what it is supposed to measure (Brink 1991:35). To enhance the validity of this study, the following steps were taken:

- $\quad$ Respondents were drawn from each district of Swaziland

- The literature was examined to identify variables to be delineated

- A nurse researcher and a statistician examined each item for its appropriateness to the research questions.

- Pretesting of the data collection instrument was done with 10 respondents who did not participate in the main study.

Tom and McNichol (1998:1204) advise that validity should be evaluated against four measures: the inter-rater validity, content validity, correctional validity and semantic validity. In this study, the inter-rater validity was enhanced by inviting an independent researcher to analyse the research results. Content validity was enhanced by comparing the findings from interviews with the literature review. These findings were found to be similar. Semantic validity was enhanced by the categories being mutually exclusive and exhaustive, as judged by the nurse researcher and the statistician consulted after the structured interview schedule had been completed.

\section{Bias}

Bias is defined by Woods and Catanzaro (1988:319) as a systematic distortion of responses by the researcher, the respondents or by the instrument. In order to decrease bias:

- The researcher was dressed in accordance with the dress code of the society and never wore a nurse's uniform.

- The researcher made use of the services of two research assistants.

- $\quad$ Research was conducted in all the regions of Swaziland.

\section{Ethical considerations}

According to Holloway and Wheeler (1998:43), research participants must grant permission voluntarily. In addition, permission also needs to be obtained from any relevant authorising body or institution. To this end, all relevant authorities were contacted in order to obtain the required permission. Permission to conduct the study was obtained from the National Health Team of Swaziland, responsible for all health activities in Swaziland, monitoring health related activities and safeguarding the health status of the population. With regard to the structured interviews that were conducted, a consent form was read to each participant, who was requested to raise a hand signifying acceptance to participate in the study, as advised by De Vos (1998:331). Literate respondents were requested to sign a consent form signifying their acceptance to participate in the study. Participation was voluntary and respondents were allowed to discontinue at any stage of the process if they wanted to do so, without incurring any disadvantage by such withdrawal. Results were presented statistically and no names of persons nor institutions were linked to any responses in order to maintain anonymity of results. This was in line with the recommendations of Brink and Wood (1998:301). No remuneration was paid to any participant. Only the researcher and the statistician had access to the completed (locked up) interview schedules.

\section{Research results}

\section{Demographic information about the respondents}

This information was gathered in order to contextualise the research results against the background information about the respondents, including their ages, economic and educational status as well as their marital status.

The ages of the 205 respondents ranged from 19 to 41 years. The majority of women $(73,2 \%$ or 150$)$ were single, whilst $26,8 \%$ (55) were married of whom $89 \%$ were married according to the Swazi customary form of marriage. In order to effect this type of marriage the man must pay a bridal prize (known as "lobola") in kind, cattle or cash to the bride's father. In this way the husband "pays" for his wife who becomes a possession of his. According to WLSA (2000:136) Swazi men exert the right over the reproductive capacity of their wives because they paid "lobola". Only $2.9 \%$ (6) of the respondents were married according to a western type marriage. All respondents adhered to the Christian religion. Of the respondents $57 \%$ were residing in rural, $30 \%$ in peri-urban and $13,0 \%$ in urban areas. 
As many as $68 \%$ (139) of the respondents had attained secondary/high school education; $6 \%$ were university scholars pursuing undergraduate studies, whilst $21 \%$ had achieved primary education and 5\% reportedly had no formal education. Of the respondents, $69.8 \%$ were unemployed, $14.1 \%$ were students pursuing tertiary education, $15.6 \%$ were wage earners and one was self employed as a traditional healer. Surprisingly, out of the 201 women who indicated the number of children they had, only $4.5 \%$ (9) had five or more children, but $16.5 \%$ (33) had 3-4 children.

\section{Socio-cultural factors posing as barriers to the use of contraceptives by Swazi women}

It was suspected, based on the researcher's knowledge and experience of the Swazi people's cultural beliefs, and supported by the literature study conducted, that sociocultural factors could pose barriers preventing Swazi women from using available contraceptive services.

\section{Cultural values}

Cultural values were perceived as deterrents to family planning practices among Swazi women. The majority of the respondents $(98.5 \%, \mathrm{n}=202)$ viewed the main responsibility of a married woman to be that of bearing children. According to WLSA (1998:174), the Swazi custom of paying a bridal price (lobola) was meant to buy the reproductive capacity of a woman. Family planning practices might be contradictory to the cultural expectation of an ideal Swazi woman to bear as many children as possible in order to justify the "lobola" paid by her husband to her father.

\section{Gender status}

Swazi women are predominantly controlled by a strong patriarchal system. Male fertility is highly acclaimed among the Swazi people, encouraging the continued existence of polygamy and even extra-marital sexual relations for men. As such $50 \%$ (101) of the female respondents' male partners did not approve their use of contraceptives and $71 \%$ of their male partners did not use contraceptives. The majority of women $(90 \%)$ were not accompanied by their partners to family planning centres. Yet, for the benefit of counselling, it is important that both partners should attend family planning sessions (Hatcher \& Kowal 1994:566).

Female fertility is of extreme cultural importance to Swazi women who are expected to bear as many children as possible and who only become accepted to be adults once they have become mothers. The findings from this study indicated that married as well as single women desired to bear many children, and 95\% (194) stated that society would stigmatise a barren woman and blame her for infertility. Furthermore, a substitute wife could be secured to produce children on behalf of a relative and "cleanse" the shame brought on the family by the infertile woman.

\section{Marital status}

Some single women used contraceptives while married women did not use any contraceptives at all. The Chi-square test demonstrated a negative association between marital status and the use of contraceptives. This finding is in line with the Swazi cultural expectation that a married woman is expected to bear children in order to justify her social position. The only way in which male fertility can be demonstrated is by the number of children borne by a man's wives. Male fertility is so highly valued in the Swazi culture that should a married Swazi man procreate a child outside of his (polygamous) marriage "... that child is brought home to be accepted and cared for by the wife. She is expected to be joyful that she can be of service to her husband" (Dlamini 2000:76). Indeed, $49 \%$ (101) of the respondents viewed permanent sterilisation to be a bad practice and they believed that fertility should terminate at the appropriate time, without any artificial interferences. The Swazi culture supports high fertility and strongly opposes permanent sterilisation.

\section{Misconceptions about contraceptives}

Contraceptives were perceived to cause infertility according to $60 \%$ (123) of the respondents and $40 \%$ (82) viewed contraceptives as being bad resulting in ill health. Other misconceptions influencing the use of contraceptives included that contraceptive injections caused infertility while oral contraceptives caused abortions and condoms were associated with promiscuity (Ziyani 2002:109-112). Sixty percent of the respondents were not informed about contraceptives and they stated that no information about family planning issues was available in their communities and that no such education programmes were available at their schools.

\section{Abortion issues}

The majority of the respondents ( $86 \%$ or 166 ) regarded abortion to be murder and a criminal offence punishable by law (reflecting the legal situation regarding abortion in Swaziland). However, 89.2\% (173 out of 194 respondents) acknowledged that abortion was rife in the Swazi society, supporting the observation that laws do not succeed in preventing abortions from taking place in countries where abortions are punishable by law. Furthermore countries where abortion statistics are unavailable, cannot assume that abortions do not take place in these countries (Bankole, Singh \& Haas 1999:69).

\section{Health issues}

Contraceptive health practices are influenced by the people's culture and by the availability and accessibility of such services. The most readily available contraceptives according to $81 \%$ (167) of the respondents were pills, injections were mentioned by $47 \%$ (97) and condoms by $40 \%$ (82) of the respondents. Family planning counselling was offered according to 53\% (108) of the respondents. Family planning clinics operated during week days according to $69 \%$ (141) of the respondents and the waiting time was longer than 30 minutes per visit. Family planning providers advised $10 \%$ of the respondents to obtain their partners' consent before they could receive any contraceptives. This finding confirmed the minority status of women by requiring a male partner to decide when and how a woman could control her fertility. The family planning services were 
substandard according to $60 \%$ of the respondents who complained about the negative attitudes displayed by family planning providers toward their clients.

\section{Conclusions and recommendations}

In order to avoid unnecessary repetitions, each conclusion will be followed by at least one relevant recommendation to address the issue at stake. The study revealed that the following factors acted as barriers for Swazi women to use contraceptives:

\section{- Value of children in the Swazi culture}

The majority of the respondents $(83 \%)$ desired additional children. Children were perceived to enhance women's social status, explaining why Swazi women desired additional children. The use of contraceptives might impact negatively on Swazi women's social status. The recommendation based on this finding is to educate women of all ages regarding the use of contraceptives to space the births of their children to enhance their own well being, as well as that of their families, rather than to focus on limiting the number of children borne by individual Swazi women. Reducing the infant and child mortality rates in Swaziland, would be an essential prerequisite for any women to use contraceptives who expect some of their children to die during childhood.

\section{- Misconceptions about contraceptives}

There were misconceptions regarding the use of contraceptives, including condoms. Thus it is recommended that sexuality and family planning education should be included in the school curriculum. Out of school adolescents need to be taught at community level as well as in families. Family planning services should be made available to adolescents at specific adolescent clinics where they would not encounter their aunts, mothers, teachers or any other significant adults.

\section{- Gender issues}

As $50 \%$ of the respondents indicated that their partners disapproved their use of contraceptives, and as $90 \%$ of the respondents' partners did not accompany them to family planning centres, male opposition to the use of contraceptives could be assumed. Thus it is recommended to promote male participation in family planning decisions, through education, values clarification sessions and peer education. Swazi women should be encouraged to obtain educational qualifications in order to earn their own incomes and to become financially and socially more independent from men's decisions.

\section{- Termination of pregnancies in swaziland}

As the respondents indicated that large numbers of preg- nancies continue to be terminated in Swaziland despite the illegal nature of these operations, it is essential that the Ministry of Health investigate the desirability of legalising termination of pregnancy services in Swaziland. Efforts should also be made to compile statistics about the incidence and complications arising from illegal abortions. An unknown number of Swazi women's health and well being might be compromised by resorting to illegal abortions. Effective use of contraceptives should prevent unplanned pregnancies from occurring.

\section{- Health service issues}

Health care workers, especially nurses, who provide contraceptive services should be motivated persons who do not come across as being judgmental towards their clients, including adolescent males and females. Swaziland's health care policies should be revised enabling health care workers to supply contraceptives on demand without requiring the approval of the women's husbands/partners.

\section{Conclusive statements}

Unless and until Swazi women become empowered to make independent decisions concerning their reproduction, and unless they can implement these decisions with the help of nurses offering contraceptive services in Swaziland, these women will remain "... poor, powerless and pregnant" (Bergstrom, Molin \& Povey 1993:5 ). On a more positive note, Dlamini (2000:83) emphasised that many attempts have been made to “... maintain a patriarchal ideology amongst emaSwati. It also becomes clear on the other hand that women are becoming ever more prepared to fight this battle to their utmost".

\section{List of references}

ABDOOL KARIM, Q; ABDOOL KARIM, SS \& PRESTON-WHYTE, E 1992: Teenagers seeking condoms at family planning services, part 2: a provider's perspective. South African Medical Journal. 82 (5):360-362.

ABOUZAHR, C; VLASSORFF, C \& KUMAR, A 1996: Quality health care for women: a global challenge. Health Care for Women International, 17(5): 449-467.

ANKOMAH, A, ALOO-OBUNGA, C, CHU, M \& MANLAGNIT, A 1997: Unsafe abortions: methods used and characteristics of patients attending hospitals in Nairobi, Lima and Manila. Health Care for Women International $18(1): 43-53$.

BANKOLE, A \& SINGH, S 1998: Couples fertility and contraceptive decision making in developing countries: hearing the man's voice. International Family Planning Perspectives. 24(1):15-24.

BANKOLE, A; SINGH, S \& HAAS, T 1999: Characteristics of women who obtain induced abortion: a world-wide review. International Family Planning Perspectives. 25(2):6877. 
BARKER, GK \& RICH, S 1992: Influence on adolescent sexuality in Nigeria and Kenya. Studies in Familv Planning. 23(3):199-210

BERGSTROM, S; MOLIN, A \& POVEY, WG 1993: Poverty and reproductive health. International Maternal Health Care; Advanced International Training Programme, Department of Obstetrics and Gynaecology. Uppsala University, World Health Organisation Collaborating Centre for Research in Human Reproduction.Uppsala.

BRINK, HLL 1991: Validity and reliability in qualitative research. Curationis, 16(2):35-38.

BRINK, PJ \& WOOD, MJ 1998: Advanced design in nursing research. $2^{\text {nd }}$ edition. London: Sage.

BURNAD, P \& MORRISON, P 1994: Nursing research in action: developing basic skills. $2^{\text {nd }}$ edition. London: MacMillan.

CAMPBELL, T 1997: How can psychological theory help to promote condom use in sub-Saharan African developing countries? Journal of the Royal Society of Health. 117:186-191.

CDC see Centres for Disease Control.

CENTRES FOR DISEASE CONTROL 1999: Family planning methods and practice: Africa. 2nd edition. Atlanta: US Department of Health and Human Services.

CHIPFAKACHA, VG 1993: Attitudes of males on contraception: a KAPE survey. East African Medical Journal. 70(2):82-84.

DEVELOPMENT PLAN 1996/7-1998/9: Economic Planning Office, Ministry of Economics Planning and Development. Government of Swaziland Mbabane: Government Printer.

DE VOS, AS 1998: Research at grass roots: a prime for the caring professions. Pretoria: Van Schaik.

DLAMINI, N 1997: The current status of women's human rights in Swaziland. Human Rights in Swaziland: The Legal Response. Department of Law. Manzini: University of Swaziland.

DLAMINI, S 2000: Reaction to patriarchal codes among emaSwati in Women, Society and Constraints: a collection of contemporary South African gender studies edited by $\mathbf{J}$ Malherbe, M Kleijwegt \& E Koen. Pretoria: Unisa Press.

ERASMUS, PA \& BEKKER, M 1996: Contraception: the women's role in family planning. South African Journal of Ethnology. 19(1): 12-16.

GALVAO,L; DIAZ,J; DIAZ,M; OSIS, MJ; CLARK,S \& ELLERTSON, C 1999: Emergency contraception: knowledge, attitudes and practices among Brazillian Ostetrician-
Gynecologists. International Familv Planning Perspectives. 25(4):168-171.

GULE, G 1993: Socio-cultural constraints to family planning in Swaziland. Africa Insight. 23 (4):240-245.

HATCHER, RA \& KOWAL, D 1999: Family planning methods and practice: Africa. $2^{\text {nd }}$ edition. Atlanta: Centre for Disease Control and Prevention.

HEALTH STATISTICAL REPORT.1997: Inpatient and outpatient record. Ministry of Health and Social Welfare. Mbabane: Government Printer.

HICKS, CM 1996: Undertaking midwifery research: a basic guide to design and analysis. London: Churchill Livingstone.

HILTABIDDLE, SJ 1996: Adolescent condom use, the Health Belief Model and the prevention of sexually transmitted disease. Journal of Obstetric, Gynecology and Neonatal Nursing. 25(1): 61-66.

HOLLOWAY, I \& WHEELER,S 1998: Qualitative research for nurses. London: Blackwell Science.

HSR see Health Statistical Report.

HOLLAND, J; RAMAZANOGLU, C; SHAPE, S \& THOMPSON, R 1992: Pleasure, pressure, and Power: some contradictions of gender sexuality. The Sociological Review. 40:645-647.

KALANZI, J 1991: Cost effective foundation of health policy in a developing country: a case study for Swaziland. Masters thesis contained in UMI Dissertation Services. National Library of Canada.

KASENENE, P 1993: Swazi tradition, religion and society. University of Swaziland. Mbabane: Websters Printers.

Malherbe, J; Kleijwegt, M \& Koen, E (eds) 2000: Women, Society and Constraints: a collection of contemporary South African gender studies. Pretoria: Unisa Press.

MBIZVO, MT \& ADAMCHAK, DJ 1992: Male fertility regulation: a study on acceptance among men in Zimbabwe. The African Journal of Medicine. 32(2):52-57.

MINISTRY OF HEALTH AND SOCIAL WELFARE RE PORT 2001-2005: National Strategic Planning and Plan of Action for the Reproductive Health Initiative. Mbabane: Government Printers.

MINISTRY OF HEALTHANDSOCIAL WELFARE 2001a: National Health and Social Welfare Policy. Mbabane: Government Printer.

MINISTRY OF HEALTH AND SOCIAL WELFARE 2001b: Community-based distribution of contraceptives in three areas. Mbabane: Government Printer. 
MKHONTA, NR 1999: Men's attitudes towards family planning. Unpublished M Cur dissertation. Auckland Park: Rand Afrikaans University.

MOTSA, MS 1991: Perceptions of rural and urban adult males toward the practices of family planning in Swaziland. A project submitted in partial fulfilment of the BED (Nursing) degree. Department of Nursing Education. Gaborone: University of Botswana.

NATIONAL DEVELOPMENT STRATEGY FOR SWAZILAND 1998: A 2022 development strategy, Ministry of Economic Planning. Mbabane: Government Printer.

NATIONAL POPULATION POLICY 2001: National population policy framework for Swaziland. National population council, Ministry of Economic Planning and Development. Mbabane, Government Printer.

NATIONAL PROGRAMME OF ACTION FOR SAFE MOTHERHOOD INITIATIVE 1997-2000: Ministry of Health and Social Welfare. Mbabane: Government Printer.

NDUBANI, H \& HOJER, B 2001: Sexual behaviour and sexually transmitted diseases among young men in Zambia. Health Policy and Planning, 16 (1): 107-112.

NDS see National Development Strategy in Swaziland.

NPASMI see National Programme of Action for Safe Motherhood Initiative.

ODINEGWU, CO 1999: Family planning attitudes and use in Nigeria: a factor analysis. International Family Planning Perspectives. 25(2):86-91.

OKPALUBA, C; HLATSHWAYO, N \& KHUMALO, B 1997: Human rights in Swaziland: the legal response. Manzini: University of Swaziland.

OKORE, A 1993: Proceedings of the national workshop on population and development: focus on Swaziland, $7^{\text {th }}-9$ th October. Manzini: University of Swaziland.

OKORE, A; MAHINDI, C \& DLAMINI, S 1993: Proceedings of the national seminar on population policy for development and self-reliance in Swaziland, $7^{\text {th }}-9^{\text {th }}$ October. Manzini: University of Swaziland.

OTOIDE, VO; ORONSAYE, F \& OKONOFUA, FE 2001: Why Nigerian adolescents seek abortion rather than contraception: evidence from focus group discussions. International Family Planning Perspectives. 27(2):77-81.

POLIT, DF \& HUNGLER, BP 1995: Nursing research: principles and methods. $3^{\text {rd }}$ edition. Philadelphia: JB Lippincott.

POPULATION REPORTS 2001: Informed choice in family planning. Population reports, series J, number 50, volume $x x 1 x(1)$ : 1-39.
REES, H 1995. Contraception: more complex than just a method. Agenda. 1(27):27-35.

RUSSELL, M 1993: Women, children and marriage in Swaziland. International Journal of Sociology of the Family, 23:43-57.

RWOMIRE, A 1991: Socio-economic determinants and consequences of unplanned parenthood in Swaziland. $\mathrm{Pa}$ per Presented at National Workshop on Population and Development Focus on Swaziland, $9^{\text {th }}-11$ th October. Department of Statistics and Demography. University of Swaziland, Kwaluseni.

SENGAL, SJ 1993: Trends in population and contraception. Annals of Medicine, 25(1):51-56.

SHONGWE, JM 1993: Family planning as an aspect to family function. Paper Presented in the National Seminar on Population Policy for Development and Self-reliance in Swaziland. Seminar organized by the UNFPA/UNDESD supported training programme in demography, $7^{\text {th }}-9^{\text {th }}$ October: Kwaluseni: University of Swaziland.

SILBERSCHMIDT, M \& RASCH, V 2001: Adolescent girls, illegal abortions and 'sugar-daddies' in Dar es Salaam: vulnerable victims and active social agents. $\underline{\text { Social }}$ Science \& Medicine. 52:1815-1826.

SNAP see Swaziland National AIDS/STD Programme.

SUKATI, NA 1998: Swazi women's perceived health care needs. Journal of Agriculture. Science and Technology. 2(2):224-229.

SWAZILANDGOVERNMENT STRATEGICPLAN 20012005: Strategic plan for sexuality and family planning programmes. Mbabane: Government Printer.

SWAZILAND MIDWIFERY CURRICULUM 2000: Curriculum for the diploma and degree programmes. Mbabane, Faculty of Health Sciences, University of Swaziland.

SWAZILAND NATIONAL AIDS/STD PROGRAMME 1996: Fifth HIV sentinel surveillance. Final report. Mbabane: Ministry of Health and Social Welfare.

SWAZILAND NATIONAL AIDS/STD PROGRAMME 1998: Sixth HIV sentinel surveillance. Final report. Mbabane: Ministry of Health and Social Welfare.

SWAZLAND NATIONAL AIDS/STD PROGRAMME 2000: Seventh HIV sentinel surveillance. Final report. Mbabane: Ministry of Health and Social Welfare.

SWAZILAND STATISTICAL OFFICE 1997: Population and Demography. Ministry of Economics, Planning and Development. Mbabane: Government Printers.

TADIAR, FM, \& ROBINSON, ET 1996: Legal, ethical and regulatory aspects of introducing emergency contracep- 
tion in the Philippines. International Familv Planning Perspectives. 22(2):76-80.

TORN, A \& McNICHOL, E 1998: A qualitative study using a focus group to explore the role and concepts of the nurse practitioner. Journal of Advanced Nursing. 27:12021211.

UNICEF see United Nations Children's Fund.

UNITED NATIONS CHILDREN'S FUND 1994: Summary: situation analysis; children and women in Swaziland. United Nations Children's Fund. Mbabane: Swaziland.

WHO see World Health Organisation.

WLSA see Women and Law in Southern Africa. Research Trust.

WOMEN AND LAW IN SOUTHERN AFRICA RESEARCH TRUST 1998: Family in transition; the experience of Swaziland. Manzini: Rushman.

WOMEN AND LAW IN SOUTHERN AFRICA. RESEARCH TRUST 2000: Charting the maze: women in pursuit of justice in Swaziland. Manzini: Rushman.

WOODS, NF \& CATANZARO, M 1988: Nursing research: theory and practice. St Louis: CV Mosby.

WORLD HEALTH ORGANIZATION 1995: Communitybased distribution of contraceptives: a guide for programme managers. WHO home page at www.int/dsa/ca98/ family8.wtm\#Reproductive Health Research at WHO.

WORLD HEALTH ORGANIZATION 1998: Safe motherhood: successes and challenges. Outlook. (special issue) 16:1-8.

WORLD HEALTH REPORT 1998: Life in the $21^{\text {st }}$ Century: a vision for all. Report of the Director General. Geneva: WHO.

ZWANE, IT 2000: Knowledge of sexually transmitted diseases and attitudes towards condom use among " at risk" adolescents in Swaziland. UNISWA Research Journal of Agriculture. Science and Technologv. 3(2): 5-11. 